\title{
PISTON EFFECT ANALYSIS FOR THE METRO VENTILATION
}

\author{
Omar LANCHAVA ${ }^{1,2}$, Giorgi NOZADZE ${ }^{1}$ \\ ${ }^{1}$ Gr. Tsulukidze Mining Institute, 0186, No7, Mindeli Street, Tbilisi, Georgia \\ ${ }^{2}$ Georgian Technical University, 0177, No77, Kostava Street, Tbilisi, Georgia
}

Corresponding author:

E-mail: o.lanchava@yahoo.com

Full postal address: ZIP 0186, 7, Mindeli Street, Tbilisi, Georgia

The purpose of the present work is to assess the influence of the piston effect in the subway tunnels depending on the speed of train, geometry of tunnel and train, types of air flows and other variable characteristics. The article deals theoretical analysis of the piston effect and results of numerical modeling in the subway tunnels. Tables and graphs of changes in the generated air flows are presented, depending on the speed of the train and the degree of filling of the tunnel. It is noted that of the piston effect is characterized by two phases. In the first phase, the piston effect and changing processes of physical fields are a non-stationary, and in the second phase the processes are stabilized. For the air flow ahead of the train as well as backflow through annular space and direct air flow after the train, it is necessary to consider the influence of these phases. The speed of the circulation flow created by the piston effect, in accordance with the tunnel filling factor, is characterized by a linear relation, and the extent rate of its growth is directly proportional to the speed of the train. Maximum value of the air consumption carried out by the piston effect for the train's speed of the $40-45 \mathrm{~km} / \mathrm{h}$ range, does not exceed $90-100 \mathrm{~m}^{3} / \mathrm{s}$, in the Tbilisi metro conditions that corresponded to the speed of the stationary phase of moving, when the tunnel filling coefficient $\alpha=0.35$.

Key words: underground, piston effect, ventilation, numerical modeling, air consumption.

\section{Introduction}

In nowadays, the underground spaces of large cities should be considered as important part of underground urbanization. More precisely, different levels of underground spaces are designed to accommodate different communications for a large city and the degree of rational use of the marked shows the level of urban development in generally. The uniqueness of these spaces is typical only for large cities, and underground transport arteries occupy a special place in the modern urban planning of large cities. Consequently, the underground space should be considered 
as a natural resource, characterized by a specific location, which needs to be used rationally, since it is not renewable. Obviously that the need for effective ventilation of underground spaces is a guarantee of their safe operation, which largely depends on the orography of the earth's surface and the complex topology of the underground spaces. The complexity of topology implies not only the geometry of these spaces, but also their connection with the atmosphere and, consequently, the complexity of the aerodynamic processes that occur under the earth.

Current level of development of computer technologies allows to describe a dynamic of ventilation flows in subway tunnels with high precision by means of numerical simulation of fluids, in particular, using FDS and CFD methods. One of the important factors in terms of air distribution in subway tunnels, and passengers' safety and convenience as mentioned, is a piston effect of a train movement, which should be comprehensively studied. It must be noted that through a piston effect it is possible that uncontrolled flows of air would be found in an underground space and it is especially relevant for the stations and subway lines located at shallow depths. Proceeding from this, studying a piston effect is a topical and important issue, which draws a significant attention of scientists and engineers in recent years. In this article, a nature of distribution of ventilation flows induced by a piston effect is reviews, in the non-stationary and stationary phases, which substantially affects the determination of ventilation parameters of subway. The problem was posed for conditions of the tunnels of Tbilisi metro, the base models were made by the following data: length of tunnel - $1200 \mathrm{~m}$; Area of the tunnel cross section $20.24 \mathrm{~m}^{2}$, length of train $-80 \mathrm{~m}$; Train speed $-25-50 \mathrm{~km} / \mathrm{h}$; Acceleration of the train $-1.0-1.2 \mathrm{~m} / \mathrm{s}^{2}$; The cross section of the train cross section $-7.5 \mathrm{~m}^{2}$. Modeling and calculations were performed in the PyroSim 2016 software environment.

One of the first works for piston effect analysis was performed by G. Abramovich. He theoretically studied the relation between an oncoming airflow and train speeds on an open route and railway tunnels [1]. For experimental analysis of a piston effect, aerodynamic and hydraulic models were used too. In all of them, a train is static and complex non-stationary aerodynamic processes are studied by means of moving air [2,3] or moving water environment [2]. In the article [3], the results of physical simulation are given. The model is performed in conditions of static train in the cylinder of a large diameter, and ambient air moves by means of fans.

The same model - a static train and moving ambient air is used in later works, which are performed by means of digital technologies [4-6]. In [6] an optimization ventilation mode of 
subway side-platform station was put forward in considering of piston wind. Article [7] states that a piston effect causes a circulation of large flows of air in subway stations and tunnels and these flows should be controlled for ensuring an optimal ventilation. It should be noted that energy costs for the system of ventilation and climate control in the New York City Subway is 500 million kWh, 200 million kWh for London Subway and 50 million kWh for Barcelona Subway [8]. Obviously, the optimal control of the ventilation system means energy savings with large absolute figures, but considering the non-stationary nature of the air flows that have arisen, according to this paper, and according to [5], the airflow calculated by traditional methods is overestimated, which in reality reduces the noted economic effect.

In the article [9], an impact of a piston effect on the technological characteristics of a metro ventilation is reviews, when the coefficient of filling a tunnel by a train is $\alpha \leq 0.25$. It is stated that among the technological characteristics of ventilation, caused by a piston effect, the following flows are important: an airflow in front of a train, airflow streaming in a gap and airflow following behind a train. It is also stated that, using these flows, it is possible to determine an airflow velocity and air consumption induced by a piston effect. In [10], a wind induced by a piston effect is characterized on the 1:8 scale model. In the article [11], an impact of high and low-pressure zones caused by a piston effect is shown on the capability of a subway ventilation, and the work [12] reviews the similar issues in case of a variability of boundary conditions of numerical simulation, when the subway tunnels are equipped with one or two vertical shafts.

The articles [13-17] review the fire detection and fire prevention measures in subway stations and transport tunnels. The works [18-23] review the issues of an underground propagation of toxic mixes through a piston effect and a reduction of through flows of air caused by a piston effect, from the perspective of passengers' convenience and safety. In the article [22], the results of more than 160 studies, conducted in 20 countries of the world, on air contaminants in the underground structures of subway, are presented. The same work [22] reviews the results of observation on the ventilation air for the Barcelona Subway, in terms of dust particles, $\mathrm{CO}_{2}$ and $\mathrm{CO}$ components, in conditions of ventilation system working and its shutdown.

\section{Material and methods}

Numerical simulation was carried out in accordance with the appropriate initial and boundary conditions. In particular, the corresponding boundary condition was met on the left portal 
in the form of an oncoming airflow velocity. The marked value always corresponded to the speed of the train in the indicated range of $25-50 \mathrm{~km} / \mathrm{h}$.

The first carriage of the train was placed in various models at 200, 300 and 400 meters from the portal of station. The detailed diagram of the experiment with the train and the speed detectors is given on the figure 1 .
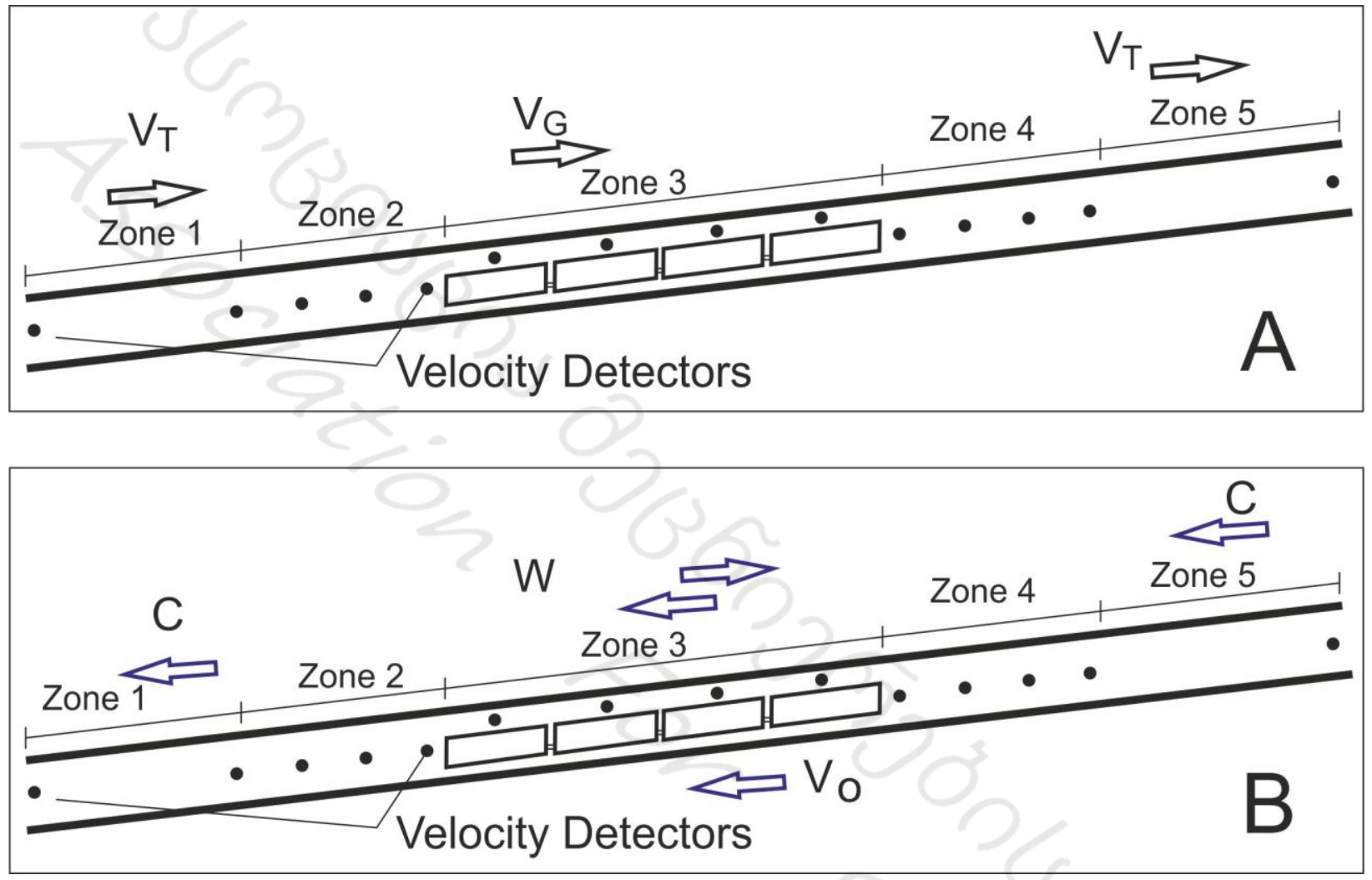

Figure 1. The scheme of velocities in cases of static and moving trains:

A-Simulated flows: $V_{T}$ - oncoming flow; $V_{G}$-flow in the annular space; B -actualflows: $V_{0}$ - speed of a train; $C$ - velocity of a circulating flow; $W$ - velocity of air flow in a annular space.

As Figure 1A shows, numerical modeling was performed in the tunnel for 5 different zones selected in according of placing of the train in the tunnel. In these zones the nature of the velocity flow changing was determined. The speed detectors in any zone were located in different distance from each other. For example, in the first and fifth zone detectors have been placed at every 100 meters (see Figure 1A, Zones 1 and 5). In the second and fourth zones, at the beginning and end of the train on the distance $20 \mathrm{~m}$, detectors were separated from each other by $5 \mathrm{~m}$ (see Figure $1 \mathrm{~A}$, Zones 2 and 4). The speed detectors in annular space between the train and the tunnel were located on every 20 meters (see Figure 1A, Zone 3). 
We introduce the notation defined by the formula (1) below

$$
\omega=\frac{V_{T}}{V_{0}}
$$

Where $\omega$ - the ratio between the velocity of oncoming flow of the air and the speed of the train; $V_{T}$ - the speed of the oncoming flow ahead of the train, $\mathrm{m} / \mathrm{s} ; V_{0}$ - train movement speed, $\mathrm{m} / \mathrm{s}$. For conditions of the Tbilisi Metro, the numerical value of mentioned ratio in accordance of the number of wagons in trains (4-car train) and the starting values for the account are given in Table 1.

Table 1

Numerical rates of the ratio between the oncoming flow of the air and the speed of the train with the starting values for the account.

\begin{tabular}{|c|c|c|c|c|c|c|c|c|}
\hline$F, \mathrm{~m}^{2}$ & $f, \mathrm{~m}^{2}$ & $\alpha$ & $F_{w}$ & $S_{w}, \mathrm{~m}^{2}$ & $R, \mathrm{~m}$ & $c_{w}$ & $\xi_{T}$ & $\omega$ \\
\hline 5.00 & 12.25 & 0.408 & 4.8 & 130 & 0.88 & 0.95 & 10.41 & 0.667 \\
\hline 6.25 & 12.25 & 0.510 & 6.0 & 147 & 0.88 & 0.95 & 10.41 & 0.570 \\
\hline 7.50 & 12.25 & 0.610 & 7.1 & 164 & 0.88 & 0.95 & 10.41 & 0.464 \\
\hline 7.50 & 20.40 & 0.370 & 7.1 & 164 & 1.27 & 0.95 & 7.67 & 0.652 \\
\hline
\end{tabular}

In the table 1 used the following designations: $F$ - the cross-sectional area of train, $\mathrm{m}^{2}$; $f$ - the cross-sectional area of the tunnel, $\mathrm{m}^{2} ; \alpha$-tunnel fill factor; $F_{w}$ - the cross-sectional area of the wagon, $m^{2} ; S_{w}$-the surface area of the wagon excluding the bottom area, $m^{2} ; R$ - equivalent radius of tunnel cross-section, $m ; c_{w}$ - coefficient of drag of a moving train; $\xi_{T}$ - Tunnel full resistance coefficient; $\omega$ - the ratio between the velocity of oncoming flow of the air and the speed of the train.

\section{Theory/calculation}

On the figure $1 \mathrm{~B}$ show schematic depictions of the real process, which takes place for the moving train in the tunnel. The moving train with the speed $V_{0}$ generates the air flow ahead the train with the speed $C$ and originates air flow rear the train with similar speed $C$. In the annular space between perimeters of train and tunnel takes place backflow with the speed $W$. The value of velocity depends on the difference in dynamic pressures between first and last wagons of the train. The magnitude of the marked speed is also affected by the ejection of air due to the motion of the train. On the marked ejection is also influenced by the rotational and translational motion of the train wheels and axes, and the movement of the airbag between the carriages, along with the train, its internal turbulent and aerodynamic effect on the circulation of air flow in the annular space. 
Depending on the specific values of the above factors, the vector of velocity may be directed towards the train movement as well as in its opposite direction. In according of tunnel filling coefficient and of velocity of the train regarding the sizes of which were used to model, for Tbilisi metro conditions, basically generate air flows in the opposite direction of the train, while air flows that coincided with the direction of the train motion, are insignificant. Consequently, the reasons for the straight air flows, which were mentioned above, in this case are negligible.

The tunnel filling coefficient can be calculated using the formula (2)

$$
\alpha=\frac{F}{f}
$$

Where, $F$ - area of midship section of the wagons, $\mathrm{m}^{2} ; f$ - cross section of the tunnel, $\mathrm{m}^{2}$.

Consider the air relative movement on the condition that the train will be really motionless and only the ventilation flow will be in motion for the conditions that have been performed numerical modeling.

In the real process, the flow of air that generated with the movement of the train is divided into two components: the oncoming flow and the circulated air flow ahead and rear of the train caused by the piston effect, between which the following dependence takes place

$$
V_{T}=V_{0}-C
$$

Where $C$ - the speed of air flow caused by the piston effect at the front and rear of the train, $\mathrm{m} / \mathrm{s}$. The remaining values have already been determined.

On the other hand, in the case of a moving train (for real conditions), the oncoming stream continues its movement and flows into the annular space between perimeters of train and tunnel at relative velocity

$$
V_{G}=V_{0} \pm W
$$

Where $V_{G}$ - stream speed in the annular space, $\mathrm{m} / \mathrm{s}$. The remaining values have already been determined.

Based on the continuity equation can write

$$
V_{T} f=V_{G}(f-F)
$$

From which by means of simple transformations and with consideration formula (2) is obtained

$$
V_{G}=\frac{V_{T}}{(1-\alpha)}
$$


Thus, the formula (6) determines the stream speed in the annular space by means of numerical modeling, in conditions of the fixed train. The stream speed in the annular space in real terms (for the train in motion) also the same formula (6) is calculated.

In the tunnels of the subway, due to their relatively small length, in most cases, there is no stabilization of the speed and there is a non-stationary process changing of speeds. Based to the numerical modeling results, for the different scenarios of train speed and tunnel filling coefficients, some of which are represented in figures 2, 3 and 4, the process duration is divided into 2 phases. The focusing on these phases is due to the results of numerical modeling in the subway conditions. Dependence between the given speeds for both non-stationary and stationary phases follows down that is useful in consideration speeds of these phases

$$
\frac{V_{T}}{V_{0}}=\frac{1}{1+\frac{1}{(1-\alpha) \sqrt{\xi_{T} \frac{f}{F_{w}} \frac{1-\alpha}{1+0.004 n \frac{S_{w}}{F_{w}}}}}}
$$

Where $\xi_{T}$ - the complete tunnel aerodynamic resistivity coefficient in according of tunnel length $(l, \mathrm{~m})$, length of train $(L, \mathrm{~m})$ and of tunnel equivalent radius $(R, \mathrm{~m}) ; F_{w}$ - equivalent area of single wagon, $\mathrm{m}^{2} ; n$ - number of wagons in the composition; $S_{w}$ - area of the surface of the wagon excluding the area of bottom, $\mathrm{m}^{2}$. The remaining values have already been determined.

The tunnel resistance complete coefficient is calculated using a formula (8)

$$
\xi_{T}=1.5+0.007 \frac{l-L}{R}
$$

All of the input symbols in formula (8) have already been interpreted.

The equivalent area of the wagon is calculated by considering the value of the frontal resistance coefficient with the following formula (9)

$$
F_{e}=c_{w} F
$$

Where $c_{w}$ - the frontal resistance coefficient of the wagon.

Considering the formula (1) speed of train will be calculated by the formula (10)

$$
V_{0}=\frac{V_{T}}{\omega}
$$

While considering the formula (3), the formula (11) of circulation flow speed calculation is received 


$$
C=V_{0}(1-\omega)
$$

The air consumption originated by means of piston effect can be determined by a formula (12)

$$
Q=C f
$$

Where $Q$ - air consumption, $\mathrm{m}^{3} / \mathrm{s}$.

3.1. Numerical calculation. Changing the boundary value of the of the speed of oncoming flow ahead of the train in numerical experimentation have been carried out according to the speed of the train. The results obtained can be analyzed by one of the numerical experiments. Consider the dynamic of change of the flow speeds rate in tunnel portals, as well as in the annular space between the perimeters of tunnel and the train (Figures 2,3 and 4).

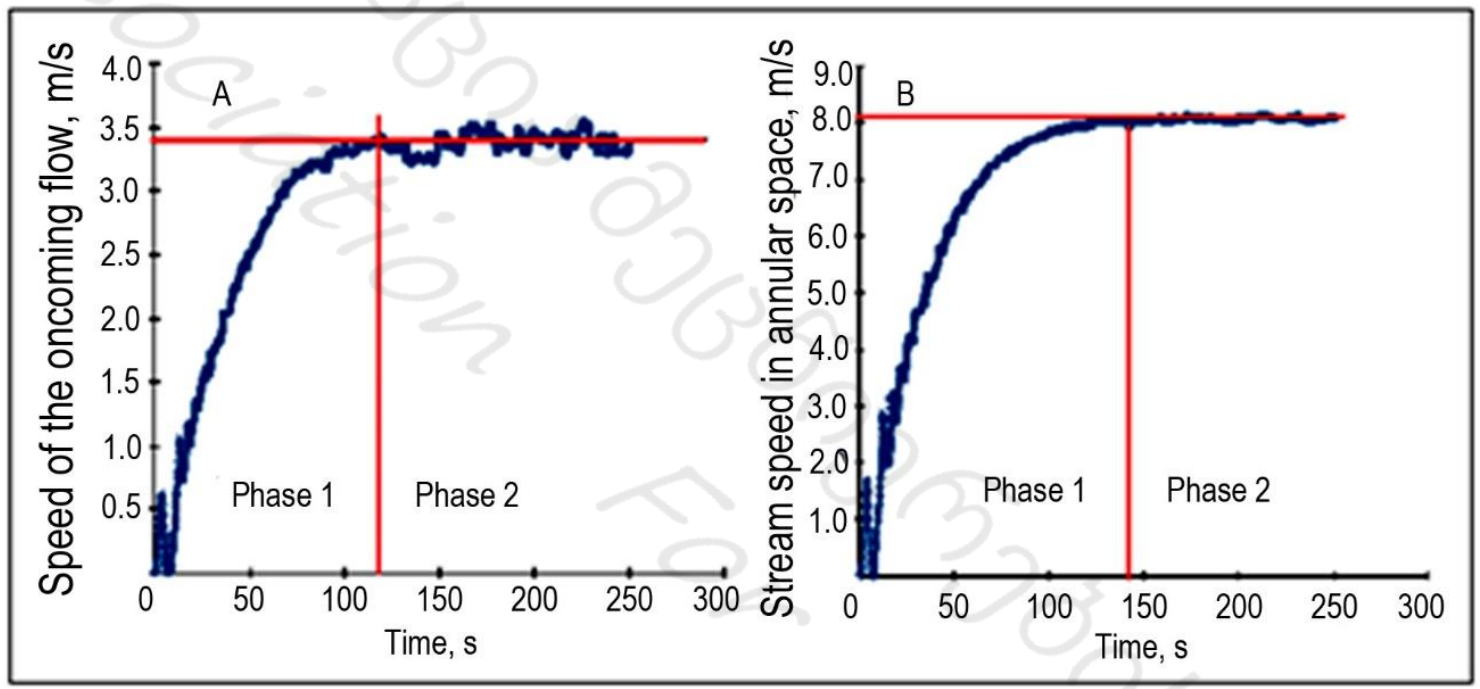

Figure 2. The dynamics of the speed of the oncoming flow (A) and the stream speed in the annular space between the train and the tunnel (B) when the speed of the train is $16.8 \mathrm{~km} / \mathrm{h}$ and $\alpha=0.61, \omega=0.47$.

From the presented figures it is well illustrated that the dynamics of ventilation flows can be divided into two phases, 1 - the non-stationary and 2 - the stationary phases. By means of these phases should also be characterized all the flows of air that will be originated out by the underground trains.

According to numerical modeling results, the average speed of circulation flow in the nonstationary phase is less than in the stationary phase compared to the same flow rate. This could also be noted a priori, since in the non-stationary phase the changing values are both the speed of the train and the losses caused by the turbulence of the air flow. 


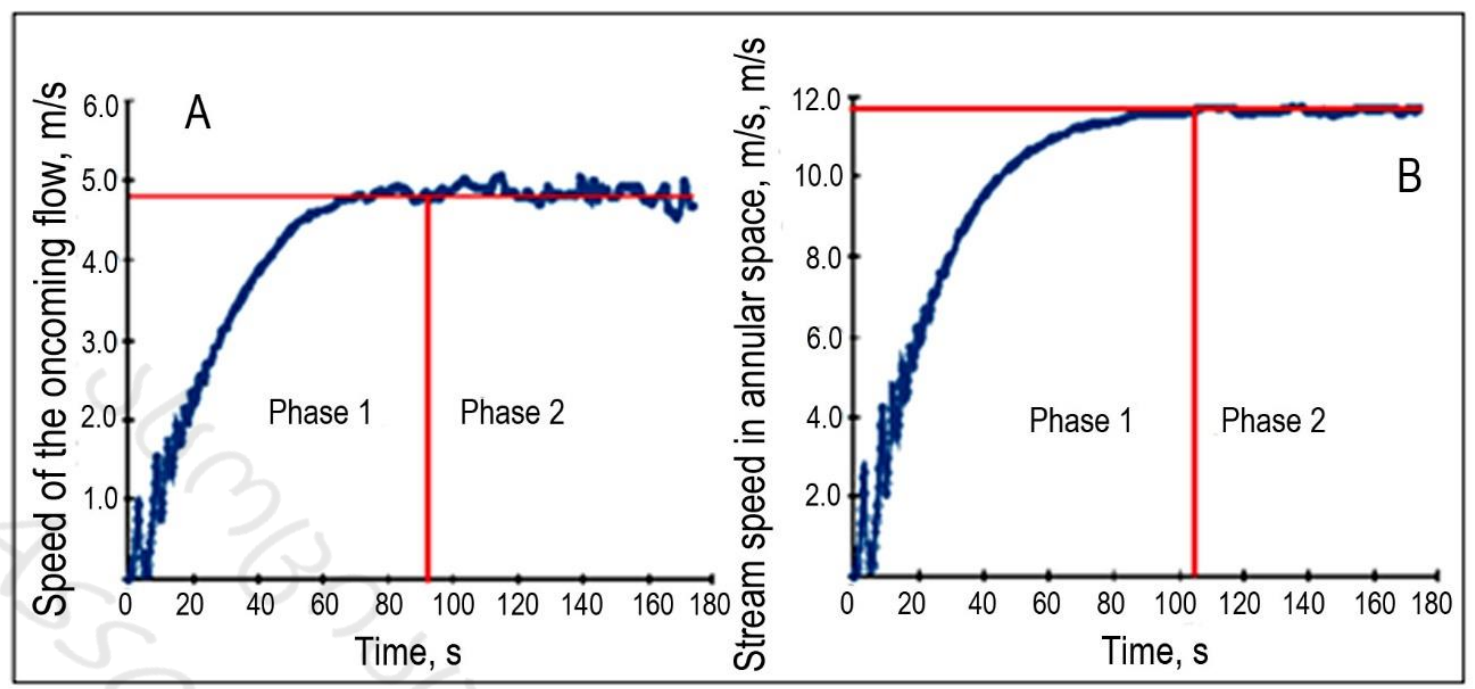

Figure 3. The dynamics of the speed of the oncoming flow (A) and the stream speed in the annular space between the train and the tunnel (B) when the speed of the train is $36.8 \mathrm{~km} / \mathrm{h}$ and $\alpha=0.61, \omega=0.47$.

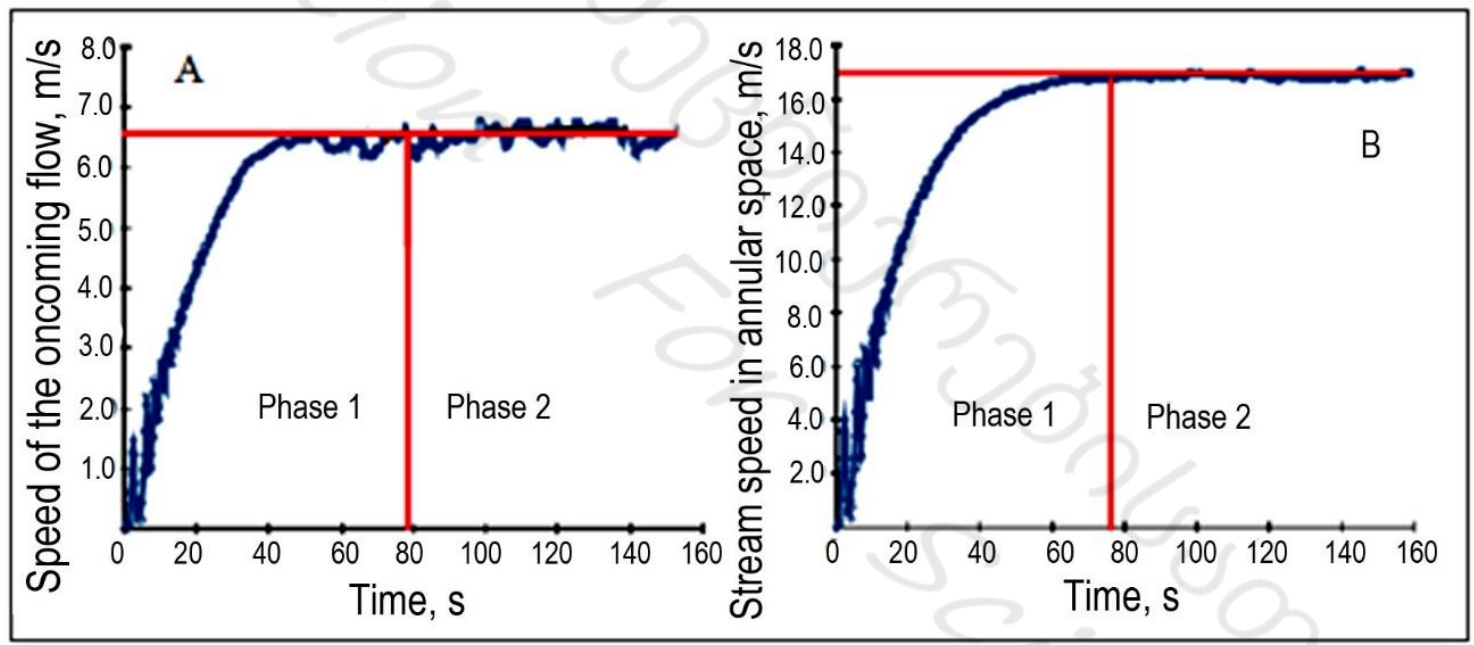

Figure 4. The dynamics of the speed of the oncoming flow (A) and the stream speed in the annular space between the train and the tunnel (B) when the speed of the train is $49.8 \mathrm{~km} / \mathrm{h}$ and $\alpha=0.61, \omega=0.47$.

\section{Results and Discussion}

Graphs compiled by numerical modeling results are given in Figure 5, from which show that circulation air flow generated by piston effect characterized by direct proportional dependence with speed of the train and tunnel filling rate.

It is noteworthy that air consumption, due to the circular flow of piston effect, when the speed of train is in the range of $40-45 \mathrm{~km} / \mathrm{h}$, may vary from 90 to $100 \mathrm{~m}^{3} / \mathrm{s}$. 


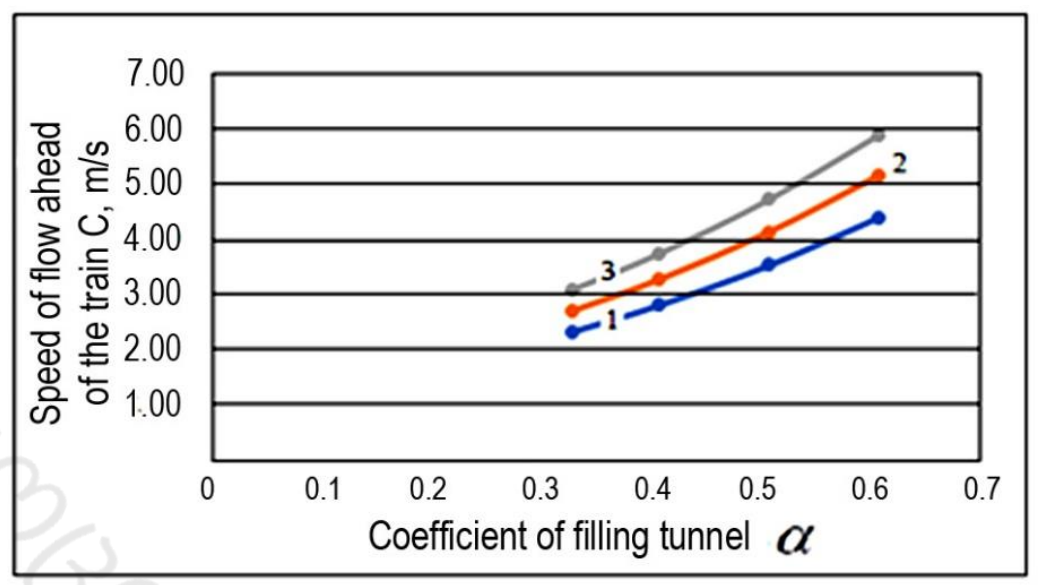

Figure 5. Changing of circulation flow speed by tunnel filling coefficient for the trains speeds, $\mathrm{km} / \mathrm{h}: 1$ $V_{0}=30 ; 2-V_{0}=35 ; 3-V_{0}=40$.

According to the tunnel filling coefficient, the changing of the circulation flow speed is given in figure 6 .

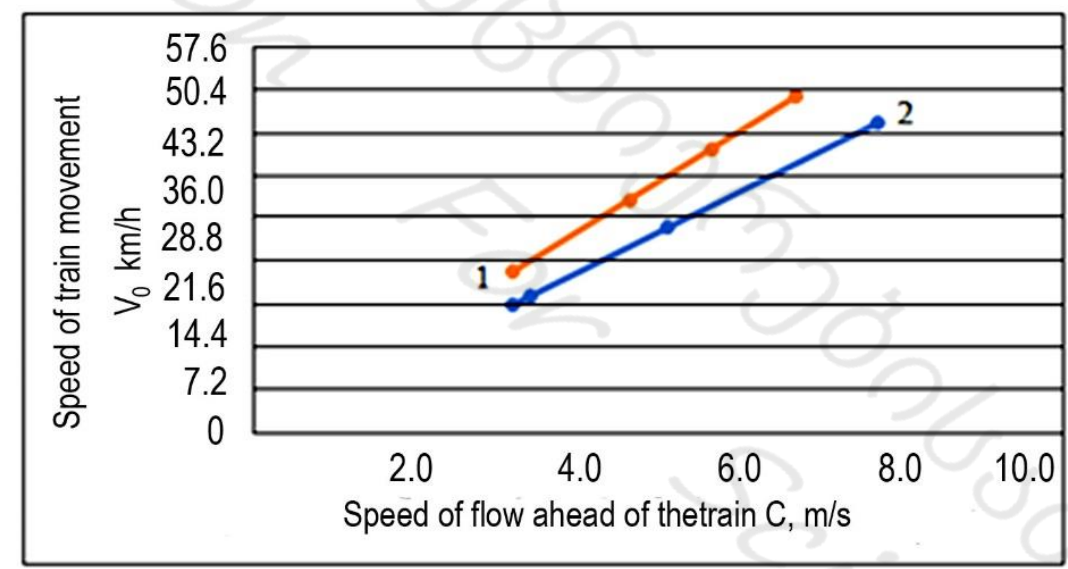

Figure 6. Changing of circulation flow speed $C$ by the speed of the train when: $1-\alpha=0.57 ; 2-\alpha=0.61$.

Figure 7 shows the nature of variation of speeds the oncoming and the circular flows in according of the different tunnel filling coefficient. The sum of the oncoming flow and the circulation flow ahead of the train should be in any case equaled the speed of the train according to which the numerical modeling was performed.

Based on the analysis of the oncoming flow speeds for simulated processes, it is possible to introduce the characteristic coefficient of the level of non-stationarity of the process by the phase duration 


$$
K_{t}=\frac{t_{n t}}{t_{p}}
$$

Where $t_{n t}$ - duration of non-stationary phase, $\mathrm{c} ; t_{p}$ - Complete duration of modeled process, $\mathrm{c}$.

So, $K_{t}$ to satisfy the inequality $0 \leq K_{t} \leq 1$.

From the inequality shows that the process is completely non-stationary when $K_{t}=1$ and when $K_{t}=0$, it is stationary. In all other cases, there will be several indicators of phase ratio in the process to be discussed. In the simulated cases, the class of such processes takes place (see Fig. 2A, 3A, 4A).

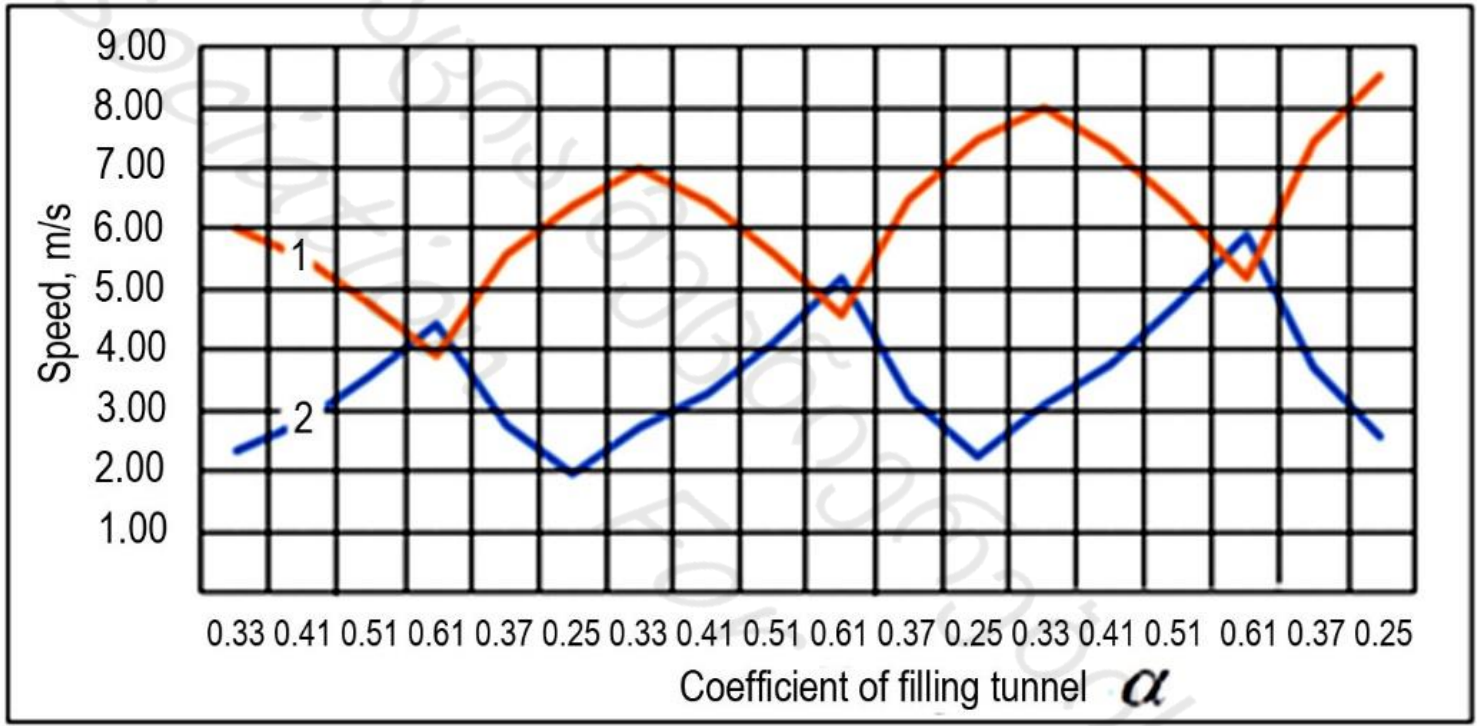

Figure 7. Variation of speeds the oncoming and the circular flows in according of the tunnel filling coefficient: 1 - the speed of the oncoming flow; 2 - the speed of circulation flow.

By means of the speed of the train on account of formula (11) is determined the speed of the circulatory flow generated by the piston effect, and by the formula (12) - the air expenditure generated by the same piston effect. If necessary, it is possible to define oncoming air flow speeds as well as air flow in annular space between the perimeters of tunnel and train. It should be taken into account that air expenses are the same for both streams. Thus, with the presented material, it is possible to determine and analyze all the technological indicators of ventilation according to numerical modeling data.

4.1. Comparison of theoretical and experimental results. It is also noteworthy that the results obtained from numerical calculations in the oncoming flow of air and the flow of air in 
annular space through our research are in good standing with theoretically calculated values. The margin of error does not exceed $7.2 \%$ (see Table 2).

Table 2

Comparison of the characteristic values of ventilation flows obtained from numerical experiments trough a theoretical analysis when $\alpha=0.61$ and $\omega=0.47$.

\begin{tabular}{|c|c|c|c|c|c|}
\hline $\begin{array}{c}\text { Speed of } \\
\text { train } \\
V_{0}, \mathrm{~km} / \mathrm{h}\end{array}$ & $\begin{array}{c}\text { Speed of } \\
\text { oncoming flow } \\
\text { (Theory) } \\
V_{T}, \mathrm{~m} / \mathrm{s}\end{array}$ & $\begin{array}{c}\text { Speed backflow in } \\
\text { annular space } \\
\text { (Theory) } \\
V_{G}, \mathrm{~m} / \mathrm{s}\end{array}$ & $\begin{array}{c}\text { Speed of oncoming } \\
\text { flow (experiment) } \\
V_{T_{-} E X}, \mathrm{~m} / \mathrm{s}\end{array}$ & $\begin{array}{c}\text { Speed of oncoming } \\
\text { flow (experiment) } \\
V_{G-E X}, \mathrm{~m} / \mathrm{s}\end{array}$ & $\begin{array}{c}\text { Percentage } \\
\text { error } \\
\%\end{array}$ \\
\hline 26.0 & 3.4 & 8.7 & 3.4 & 8.1 & 6.9 \\
\hline 36.8 & 4.8 & 12.3 & 4.8 & 11.6 & 5.8 \\
\hline 49.8 & 6.5 & 16.6 & 6.5 & 15.4 & 7.2 \\
\hline
\end{tabular}

From the comparison of theoretical analysis and numerical experiments, the experimental data is closer to the theoretical, which gives an additional basis for the calculation of the number of circulation air flow with consideration of influence of non-stationary phase of the processes.

As was mentioned above, according to the speed of the train, it is possible to calculate the speed of oncoming air flow, the speed of backflow in annular space, the speed of circulation air flow ahead and rear of the train as well as air consumption generated thanks to the piston effect of moving train. These data are mainly intended for calculation of ventilation. In addition, for the forecasted purposes, the calculation of the circulation flows in front and behind the train is more favorable for realistic conditions trough the train speeds, which are shown in Figure 7.

\section{Conclusions}

- As a result of numerical experiments, it is shown that the dynamics of the oncoming flow and backflow in the annular space is characterized by stationary and non-stationary phases, which should be taken into account in determining the flow velocities that arise by moving train. The extent rate of non-stationarity of the process $K_{t}$ for train speeds $(25-50 \mathrm{~km} / \mathrm{h})$ is close to $1 / 2$, which is a sufficient basis in order to take into consideration the mentioned phases for calculating of the air circulate speed and of air consumption;

- The speed of the circulation flow created by the piston effect, in accordance with the tunnel filling factor, is characterized by a linear relation, and the extent rate of its growth is directly proportional to the speed of the train; 
- Maximum value of the air consumption carried out by the piston effect for the train's speed of the $40-45 \mathrm{~km} / \mathrm{h}$ range, does not exceed $90-100 \mathrm{~m}^{3} / \mathrm{s}$, in the Tbilisi metro conditions that corresponded to the speed of the stationary phase of moving, when the tunnel filling coefficient $\alpha=0.35$.

\section{Acknowledgements}

This work was supported by Shota Rustaveli Georgian National Science Foundation (SRNSF) [Grant number 216968].

\section{References}

[1] Abramobich G.N. Prikladnaia gazovaia dinamika. 1991; Moscow: 600, (in Russian).

[2] Tsodikov V.Y. Ventiliacia i teplosnabjenie metropolitenov. 1975; Moscow: 568, (in Russian).

[3] Xu S.S. Piston wind and environmental conditions in the tunnel. Electric Appliances, 1987; 3: 42-47.

[4] Pan S., Fan L., Liu J., Xie J., Sun Y., Cui N., Zhang L., Zheng B. A Review of the Piston Effect in Subway Stations. Advances in Mechanical Engineering. 2013: http//dx.doi.org/10.1155/2013/950205.

[5] Xue P., You S., Chao J., Ye T. Numerical investigation of unsteady airflow in subway influenced by piston effect based on dynamic mesh. Tunneling and Underground Space Technology. 2014; 40: 174-181.

[6] Yuan F.-D., You S. CFD simulation and optimization of the ventilation for subway sideplatform. Tunneling and Underground Space Technology. 2007; 22(4): 474-482.

[7] Lin C., Chuah Y.K., Liu C. A study on underground tunnel ventilation for piston effects influenced by draught relief shaft in subway system. Applied Thermal Engineering. 2008; 28(5-6): 372-379.

[8] González M.L., Vega M.G., Oro J.M.F. and Marigorta E.B. Numerical modeling of the piston effect in longitudinal ventilation systems for subway tunnels. Tunneling and Underground Space Technology. 2014; 40: 22-37.

[9] Lanchava O., Ilias N., Nozadze G., Radu S., Moraru R., Khokerashvili Z., Arudashvili N. The Impact of the Piston Effect on the Technological Characteristics of Ventilation in the Subway Tunnels. Proceedings of 8th International Symposium "Occupational Health and Safety" SESAM-2017. Bucharest, Romania, 2017; 2: 342-352.

[10] Li Z., Chen C., Yan L., Pan S., Zhang L. "Cross-Ventilation" Effect of Piston Wind and Energy-Saving Evaluation for the Ventilation and Air Condition in Subway Station. Proceedings of the 8th International Symposium on Heating, Ventilation and Air Conditioning. 2017: 147-156. 
[11] Wang F., Wang M., He S., Deng Y. Computational study of effects of traffic force on the ventilation in highway curved tunnels. Tunneling and Underground Space Technology. 2011; 26(3): 481-489.

[12] Yan W., Naiping G., Lihui W., Xiping_W. A numerical analys is of airflows caused by trainmotion and performance evaluation of a subway ventilation system. 2014; 23(6): 854-863.

[13] Meng N., Hu L., Wu L., Yang L., Zhu S., Chen L., Tang W. Numerical study on the optimization of smoke ventilation mode at the conjunction area between tunnel track and platform in emergency of a train fire at subway station. Tunneling and Underground Space Technology. 2014; 40:151-159.

[14] Chiu C.-W., Lu T., Chao H.-T., Shu C.-M. Performance assessment of video-based fire detection system in tunnel environment. Tunneling and Underground Space Technology. 2014; 40:16-21.

[15] Lanchava O., Ilias N., Nozadze G. Some problems for assessment of fire in road tunnels. Supplement of Quality-Access to Success. Bucharest. 2017; 18(S1):69-72.

[16] Ilias N., Lanchava O., Nozadze G. Numerical modelling of fires in road tunnels with longitudinal ventilation system. Supplement of Quality-Access to Success. Bucharest. 2017; 18(S1):85-88.

[17] Lanchava O., Abashidze G., Tsverava D. Securing fire safety for underground structures. Supplement of Quality-Access to Success. Bucharest. 2017; 18(S1):47-50.

[18] Kim K.-H., Ho D.X., Jeon J.-S., Kim J.-C. A noticeable shift in particulate matter levels after platform screen door installation in a Korean subway station. Atmospheric Environment. 2012; 49:219-223.

[19] Moreno T., Martins V., Querol X., Jones T., BéruBé K., Minguillón M.C., Amato F., Capdevila M., de Miguel E., Centelles S., Gibbons W. A new look at inhalable metalliferous airborne particles on rail subway platforms. Science of the Total Environment. 2015; 505:367-375.

[20] Li G., You S. A New System to Reduce Air Pollution in Metro Platform. Procedia Environmental Sciences. 2011; 11:1454 - 1458.

[21] Wang J., Zhao L., Zhu D., Gao H.O., Xie Y., Li H., Xu X., Wang H. Characteristics of particulate matter (PM) concentrations influenced by piston wind and train door opening in the Shanghai subway system. Transportation Research. 2016; D47:77-88.

[22] Xu B., Hao J. Air quality inside subway metro indoor environment worldwide: A review. Environment International. 2017; 107:33-46.

[23] Lanchava O., Ilias N., Nozadze G., Radu S.M., Moraru R.I., Khokerashvili Z., Arudashvili N. FDS MODELLING OF THE PISTON EFFECT IN SUBWAY TUNNELS. Environmental Engineering and Management Journal. April 2019, Vol. 18 (4): 317-325. 